\title{
Comparison of the in vitro Effect of Chemical and Herbal Mouthwashes on Candida albicans
}

\author{
Somayeh Talebi ${ }^{1}$; Azar Sabokbar ${ }^{1, *}$; Majid Riazipour ${ }^{2,3}$; Mohsen Saffari ${ }^{4}$ \\ ${ }^{1}$ Department of Microbiology, College of Basic Sciences, Karaj Branch, Islamic Azad University, Karaj, IR Iran \\ ${ }_{3}^{2}$ Applied Microbiology Research Center, Baqiyatallah University of Medical Sciences, Tehran, IR Iran \\ 3 Department of Parasitology and Mycology, School of Medicine, Baqiyatallah University of Medical Sciences, Tehran, IR Iran \\ Department of Parasitology and Mycology, School of Medicine, Baqiyatallah University of Medical Sciences, Teh
${ }^{2}$ Department of Health Education, School of Health, Baqiyatallah University of Medical Sciences, Tehran, IR Iran \\ ${ }^{*}$ Corresponding author: Azar Sabokbar, Department of Microbiology, College of Basic Sciences, Karaj Branch, Islamic Azad University, Karaj, IR Iran. Tel: + 98-2634182454, E-mail: \\ sabokbar@kiau.ac.ir
}

Received: June 2, 2013; Revised: June 16, 2013; Accepted: June 25, 2013

\begin{abstract}
Background: During the recent decades research has focused to find scientific evidence for the effects of herbal medicines. Researchers are interested in herbal remedies for medication and aim to substitute herbal material instead of chemical formula with limited side effects for human being.

Objectives: The aim of the current study was to compare the in vitro effect of herbal and chemical mouthwashes against Candida albicans. Materials and Methods: In this research, we used a standard strain of $C$. albicans, PTCC 5027. The suspension was made by a fresh culture of C. albicans (24 hours) and the optical density (turbidity equating to a McFarland standard of 0.5 ) was read at $530 \mathrm{~nm}$. The C. albicans suspension was cultured on Sabouraud dextrose agar plate. Next, two wells were filled with mouthwashes and after incubation at $30^{\circ} \mathrm{C}$ for 24 hours, the inhibition zone was measured. Minimum inhibitory concentration (MIC) and minimum fungicidal concentration (MFC) of mouthwashes were determined. Data were analyzed using the SPSS software, independent T-tests and one-sided variance analysis (ANOVAone way).

Results: Based on these findings on agar diffusion with $(\mathrm{P}=0.764)$, MIC and MFC tests $(\mathrm{P}=0.879)$, there were no significant differences between the antifungal effect of herbal and chemical mouthwashes.

Conclusions: This study showed that, chemical mouthwashes acted better than herbal mouthwashes and among different chemical mouthwashes, Oral B was most effective.
\end{abstract}

Keywords: Mouthwash; Candida albicans; Minimum Inhibitory Concentration

\section{Background}

Candida albicans is considered as part of the normal flora of the mouth, which doesn't cause disease but under unfavorable local conditions, such as poor oral hygiene (1), wearing of denture (2) and general predisposing factors such as high carbohydrate diet, smoking (3), diabetes (4) malnutrition, leukemia, chemotherapy, genetic disorders (5), long term antibiotic therapy (6), corticosteroid therapy (7), senility (8), radiotherapy (9) and cancer (10)can cause candidiasis. Using mouthwashes is a common way to controlling the C. albicans population in the mouth, which are used widely in dentistry $(11,12)$. Mouthwashes have been recommended for the prevention and control of oral diseases, especially for the control of oral microorganisms (13). They usually contain water and some active components such as antibiotics, antifungal and anti-inflammatory substances. Some mouthwashes have been found to enhance the removal process and elimination of microorganisms (14).

Nowadays, different types of medicine have been used for the treatment of oral problems. Most of them are chemical and have many side effects; consequently re- searchers are interested in herbal remedies for medication and aim to substitute herbal material instead of chemical formula with limited side effects for human beings (15). Different mouthwashes are available in the Iranian market but there is no information about their efficiency differences. Among different herbal and chemical mouthwashes, which are available in the Iranian market (Table 1), chlorhexidine and persicac have been more considered. Chlorhexidine was introduced as an antiseptic agent with activity against different organisms such as bacteria, viruses and different types of fungi including C. albicans, which causes oral candidiasis (16). Different studies on chlorhexidine have demonstrated its potential to prevent oral complications, such as the occurrence of chronic or opportunistic infections (17).

In order to overcome the effects of chemical drugs, the World Health Organization (WHO) has advised researchers to investigate the possible use of natural products such as herb and plant extracts (18). One of the agents considered as an alternative to chlorhexidine is a plant called Salvadora persica or "Miswak". S. persica herbal

Copyright (C) 2014,Ahvaz Jundishapur University of Medical Sciences; Published by Kowsar. This is an open-access article distributed under the terms of the Creative Commons Attribution License, which permits unrestricted use, distribution, and reproduction in any medium, provided the original work is properly cited. 
mouthwash contains three medicinal plants, S. persica, Yarrow and Mint. Furthermore, WHO encourages the use of chewing S. persica sticks (Miswak) as an effective oral hygiene procedure $(19,20)$. S. persica, a very popular plant in the Middle East, contains a number of identified antimicrobial and other prophylactic components including volatile oils, flavonoids, alkaloids, steroids, terpenoids, saponins and carbohydrates $(18,21)$.

Currently, a herbal drug is defined as a remedy derived from plants (roots, leaves, flowers, fruits, seeds) and other natural sources which can be used for therapeutic purposes and its active chemical constituents provide the basis for pharmaceutical synthesis (21). Different studies have indicated that, using a mouthwash in patients with systemic infection could decrease fungal and bacterial colonization in the mouth cavity. McCourtie et al. (22) investigated the effect of chlorohexidinegluconate on Candida adhesion to acrylic denture and concluded that fungal colonization decreases by using chlorohexidine. A study by Pizzo et al. (23) indicated a considerable decrease in the colonization of adhesive Candida to epithelial cells in individuals using chlorohexidine. Nayak et al. (24) investigated the effect of chlorohexidine on dental plaque and concluded that chlorohexidine is an effective agent in decreasing dental plaque and colonization of microorganisms in plaque.

Among mouthwashes, most researches have focused on chlorhexidine against C. albicans and there is a lack of complete information about other mouthwashes especially herbal ones. The current study tried to evaluate the effect of the anticandidial activity of different mouthwashes, which are used in the Iranian market and attempted to find the most effective mouthwash for patients who are susceptible for candidiasis.

\section{Objectives}

The purpose of the current research was to compare the effect of chemical and herbal mouthwashes on C. albicans.

\section{Materials and Methods}

\subsection{Strain of C. albicans}

In this study, a standard strain of C. albicans was used, NO. PTCC 5027.The standard strain was cultivated in Sabouraud dextrose agar, SDA (Merck, Germany) and placed at $30^{\circ} \mathrm{C}$ for 24 hours until activated.

\subsection{Mouthwashes}

Different types of mouthwashes were used for this study. Chemical mouthwashes such as Vi-one (Rojn Cosmetic Lab Co, Tabriz, Iran), Fluorine (World Health Laboratories Co, Tehran, Iran), Hexodine (World Health Laboratories Co, Tehran, Iran), Oral B (Grossgerau Co, Hessen, German), Sensodyne (GSK Co, London, UK), Foramen (Guarnizo Co, Cantabria, Spain), Epimax (Emad Pharmaceutical Co, Esfahan,
Iran), Chlorohexidine (Shahre Daru Laboratories Co, Tehran, Iran), Fluoride (Shahre Daru Laboratories Co, Tehran, Iran), anti-septic Irsha (Shafa Cosmetic Laboratories Co, Tehran, Iran), anti-plaque Irsha (Shafa Cosmetic Laboratories Co, Tehran, Iran ), Benzydamine (Behvazan Co, Rasht, Iran), Colgate (Kucukyali Co, Estanbol, Turkey), and herbal mouthwashes such as Matrica (Barij Essence Pharmaceutical Co, Kashan, Iran), S. persica (Porsina Pharmaceutical Co, Tehran, Iran), and Corpore Sano (Disna. SA Co, Barcelona, Spain) were used. The compositions of all of the mouthwashes are provided in Table 1.

\subsection{Agar Diffusion}

A suspension was made by physiological saline (Samen, Iran) and fresh culture of C. albicans (24 hours) and the OD (with turbidity equating to a McFarland standard of 0.5) was read at $530 \mathrm{~nm}$ wave length by a spectrophotometer (Pars Teb Novin, Iran), in which there were $2.5 \times 10^{6} \mathrm{CFU} /$ $\mathrm{mL}$ colonies in each milliliter (optical density at $530 \mathrm{~nm}$, 0.12 ). Next, $10 \mu \mathrm{L}$ of the suspension was transferred to SDA medium and two wells were made with suitable distance in culture medium, filling with mouthwashes. To decrease error, the test was repeated 4 times. Plates were placed in the incubator (Behdad Medical Production, Iran) at $30{ }^{\circ} \mathrm{C}$ for 24 hours (25). Inhibition zone was measured and recorded using a Collis (Kiya Sanat Khavaran, Iran) (26). For each mouthwash, one control plate containing mouthwash and sterilized distilled water was prepared.

\subsection{MIC Measurement}

To determine the minimum inhibitory concentration for each mouthwash, a serial dilution was prepared according to the CLSI protocol (27). The lowest concentration of mouthwash that prevented turbidity (growth) of C. albicans was considered as the minimum inhibitory concentration. This method was conducted based on turbidity clearance.

\subsection{Minimum Fungicidal Concentration (MFC) Measurement}

To determine the minimum fungicidal concentration of fungus, $10 \mu \mathrm{L}$ of specimens were taken from the MIC (last clear tube) and two last tubes were poured in SDA, incubating at $30{ }^{\circ} \mathrm{C}$ for 24 hours. The lowest concentration of mouthwash that prevented the growth of C. albicans determined by sub-culturing of the last clear MIC tube on SDA and refers to fungicidal activity. This procedure was conducted to allow more accuracy and control error. Colony counts of less than four, indicated no growth while more than four indicated growth (27).

\subsection{Statistical Analysis}

The data were analyzed with the SPSS software $\left(18^{\text {th }}\right.$ edition), using independent T-test and one-sided variance analysis (one way ANOVA) with $\mathrm{P}<0.05$. 
Talebi S et al.

Table 1. Ingredients of Various Mouthwashes Tested For Anticandidial Potential

\begin{tabular}{lcccc}
\hline Name & Batch No. & Manufacture Date & Expiry Date & Ingredients as Listed on Packages \\
\hline Oral B & KT 13 & October 2010 & August 2013 & $\begin{array}{c}\text { Aqua, glycerin, polysorbate 20, aroma, methylparaben, ce- } \\
\text { tylpyridinium, chloride, sodium fluoride, sodium benzo- } \\
\text { ate, propylparaben, CI42051, CI 47005. }\end{array}$
\end{tabular}

$\begin{array}{lccc}\text { Sensodyne } & 1241033 & \text { August 2011 } & \text { August 2013 } \\ \text { Vi-one } & 2231 & \text { July 2012 } & \text { July 2014 }\end{array}$

Sodium flouride.

Deionized water, sorbitol,glycerine, ploxamer 407, polyethylene glycol, perment ethanol, menthol, sodium methyl paraben, aspartame, sodium propyl paraben, citric acid, sodium fluoride $0.05 \%$, cetylpyridinium chloride $0.05 \%$, CIN 42090.

\begin{tabular}{|c|c|c|c|c|}
\hline Fluorine & 90-F1-O1 & April 2011 & April 2013 & $\begin{array}{l}\text { Sodium flouride, cetylpyridinium chloride, zinc ions, glyc- } \\
\text { erin, sorbitol, sodium fluoride. }\end{array}$ \\
\hline Hexodine & $\mathrm{C1}-03$ & July 2012 & July 2014 & Aqua, glycerin, CI 42090. \\
\hline Epimax & 2011 EPM-11 & December 2011 & December 2013 & $\begin{array}{l}\text { Sorbitol, propylene glycol, tetra sodium pyrophosphate, } \\
\text { citric acid, polysorbate } 20 \text {, polysorbate60, chlorhexidin- } \\
\text { edigluconate, sorbic acid, menthol, sodium fluoride, so- } \\
\text { dium saccharine, dye. }\end{array}$ \\
\hline Chlorhexidine & CL-06 & March 2012 & March 2014 & $\begin{array}{l}\text { Sorbitol. flavour, PEG } 40 \text { hydrogenated castor oil, alcohol, } \\
\text { CI } 16035 .\end{array}$ \\
\hline
\end{tabular}

\begin{tabular}{|c|c|c|c|}
\hline Anti-Plaque Irsha & 9058 & December 2011 & $\begin{array}{l}\text { December } 2014 \text { Alcohol, glycerin, synperonic, TSPP, SLS, benzoic acid, al- } \\
\text { lantoin, PVM/MA, benzoate, fluoride 0.05\%, saccharin, CI } \\
42090, \text { CI } 19140 .\end{array}$ \\
\hline
\end{tabular}

Anti-Septic Irsha $9022 \quad$ February $2012 \quad$ February 2015 Alcohol, synperonic, benzoic acid, benzoate, okaliptol, ty-

$\begin{array}{lcccc}\text { Benzydamine } & \text { BH. 89.16 } & \text { December 2010 } & \text { December 2013 } & \text { Hydrochloride 0.15\%. } \\ \text { Colgate } & \text { 2069 CHG11B } & \text { August 2010 } & \text { August 2013 } & \begin{array}{l}\text { Aqua, glycerin, alcohol, sorbitol, propylene glycol, polysor- } \\ \text { bate20, sodium benzoate, aroma, PVM/MAcopolymer, zinc } \\ \text { citrate, Cl 42090, sodium fluoride, tetrasodium pyrophos- } \\ \text { phate, tetrapotassium pyrophosphate, sodium saccharin. }\end{array} \\ & & & \end{array}$

\begin{tabular}{|c|c|c|c|c|}
\hline Fluoride & 14 & December 2011 & December 2014 & Sodium fluoride $0.2 \%$. \\
\hline Foramen & Ref.015 & February 2012 & February 2016 & $\begin{array}{l}\text { Sodium fluoride } 0.05 \% \text {, triclosan, aqua, sorbitol, glycerin, } \\
\text { PEG-40, castoroil, aroma, cinnamal, sodium propyl para- } \\
\text { ben, sodium benzoate, sodium saccharin, CI } 42090 \text {. }\end{array}$ \\
\hline M.chamomilla & 310038 & December 2011 & December 2013 & Matricaria chamomilla \\
\hline S. persica & 09 & September 2011 & September 2013 & Salvadora persica, Mentha spicata, Achilleamille folium. \\
\hline Corpore Sano & G0019 & March 2012 & March 2014 & $\begin{array}{l}\text { Aqua, alcohol, PEG-40, hydrogenated castor oil, aroma, } \\
\text { geraniol, sodium benzoate, sodium saccharin, Propolis ex- } \\
\text { tract, ethylparaben, propylparaben, methanol, citric acids, } \\
\text { CI } 19140, \text { CI } 42090 \text {. }\end{array}$ \\
\hline
\end{tabular}

\section{Results}

The mean diameter of inhibition zone by herbal and chemical mouthwashes has been indicated in Tables 2 and 3. The comparison of inhibition zone diameter by using chemical and herbal mouthwashes has been indicated in Figure 1. Oral B and S. persica, mouthwashes showed the highest and lowest anti-candidial activity against C. albicans in SDA, according to the inhibition zone diameter. Amount of MIC was determined by the tube dilution test, with 10 dilution tubes. The point at which growth of
C. albicans was inhibited was recognized as the minimum inhibitory concentration. Statistical analysis of the MIC and MFC amounts of chemical and herbal mouthwashes are shown in Tables 4 and 5. Comparison of the amounts of MIC and MFC by using chemical and herbal mouthwashes are indicated in Figure 2. Colgate and anti-plaque Irsha mouthwashes showed the highest amount of MIC and MFC against C. albicans (Figure 3) and Vi-one mouthwash showed the lowest amount of MIC and MFC (Figure 4). The results of the MFC were similar to MIC (Tables 4 and 5). 
Talebi S et al.

Table 2. Statistical Analysis, Mean Diameter and Standard Deviation of Inhibition Zone Exhibited by Chemical Mouthwashes Against C. albicans ${ }^{\mathrm{a}, \mathrm{b}}$

\begin{tabular}{lcccc}
\hline Types of Mouthwashes & Mean $(\mathbf{m m})$ & SD $(\mathbf{m m})$ & P value From One Way ANONA Test & Control P value \\
\hline Oral B & 23.25 & 0.65 & & \\
Sensodyne & 19.87 & 1.32 & & \\
Vi-one & 19.43 & 0.81 & & \\
Fluorine & 18.46 & 1.84 & & \\
Hexodine & 16.65 & 0.85 & & \\
Epimax & 14.37 & 0.79 & \\
Chlorhexidine & 14.21 & 0.45 & \\
Anti-Plaque Irsha & $\mathrm{R}$ & $\mathrm{R}$ & \\
Anti-Septic Irsha & $\mathrm{R}$ & $\mathrm{R}$ & \\
Benzydamine & $\mathrm{R}$ & $\mathrm{R}$ & \\
Colgate & $\mathrm{R}$ & $\mathrm{R}$ & \\
Fluoride & $\mathrm{R}$ & $\mathrm{R}$ & \\
Foramen & $\mathrm{R}$ & $\mathrm{R}$ & \\
\hline a R. means C. albicans resistance to these mouthwashes. & \\
b The units of mean and standard deviation of inhibition zone are in millimeter (mm).
\end{tabular}

Table 3. Statistical Analysis, Mean Diameter and Standard Deviation of Inhibition Zone Exhibited by Herbal Mouthwashes Against $C$. albicans $\mathrm{a}$, b

\begin{tabular}{lcccc}
\hline Types of Mouthwashes & Mean $(\mathbf{m m})$ & SD $(\mathbf{m m})$ & P value From One Way ANONA Test & Control P value \\
\hline M.chamomilla & 16.37 & 0.74 & & $\mathrm{P}<0.001$ \\
S. persica & 10.93 & 0.77 & & \\
Corporesano & $\mathrm{R}$ & $\mathrm{R}$ & & \\
\hline $\mathrm{a}$ R. means C. albicans resistance to these mouthwashes. & & \\
$\mathrm{b}$ The units of mean and standard deviation of inhibition zone are in millimeters (mm). &
\end{tabular}

Table 4. Statistical Analysis of Minimum Inhibitory Concentration and Minimum Fungicidal Concentration Exhibited by Chemical Mouthwashes Against C. albicans ${ }^{\text {a }}$

\begin{tabular}{lccc}
\hline Types of Mouthwashes & MIC and MFC $(\mathbf{m g} / \mathbf{L})$ & P value From One Way ANONA Test & Control P value \\
\hline Anti-Plaque Irsha & 0.250 & & \\
Colgate & 0.250 & & \\
Anti-Septic Irsha & 0.125 & & \\
Benzydamine & 0.125 & $\mathrm{P}<0.001$ & \\
Foramen & 0.062 & & \\
Fluoride & 0.062 & & \\
Epimax & 0.031 & & \\
Hexodine & 0.019 & & \\
Chlorhexidine & 0.015 & & \\
Fluorine & 0.007 & & \\
Sensodyne & 0.007 & \\
Oral B & 0.003 & \\
Vi-one & 0.001 &
\end{tabular}

a The unit of MIC is in $\mathrm{mg} / \mathrm{L}$.

Table 5. Statistical Analysis of Minimum Inhibitory Concentration and Minimum Fungicidal Concentration Exhibited by Herbal Mouthwashes Against C. albicans ${ }^{\text {a }}$

\begin{tabular}{lccc}
\hline Types of Mouthwashes & MIC and MFC $(\mathrm{mg} / \mathrm{L})$ & P value From One Way ANONA Test & Control P value \\
\hline S. persica & 0.093 & & \\
M. chamomilla Matrica & 0.062 & $\mathrm{P}=0.465$ & $\mathrm{P}<0.05$ \\
Corporesano & 0.062 & & \\
\hline
\end{tabular}

\footnotetext{
${ }^{\mathrm{a}}$ The unit of MIC is in $\mathrm{mg} / \mathrm{L}$.
} 


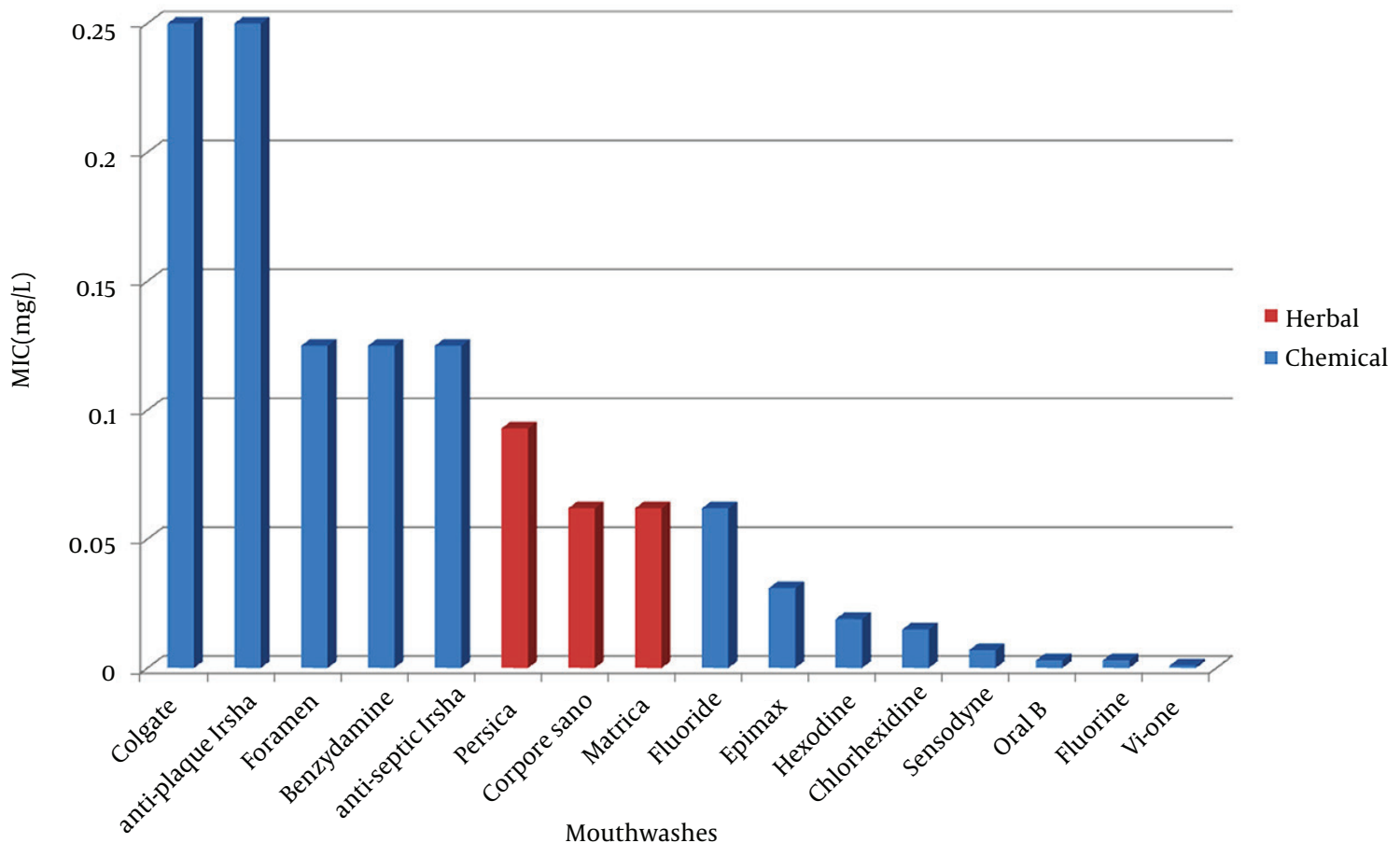

The unit of mean of inhibition zone is in millimeters (mm).

Figure 2. Comparison of the Minimum Inhibitory Concentration and Minimum Fungicidal Concentration of Chemical and Herbal Mouthwashes Against C. albicans

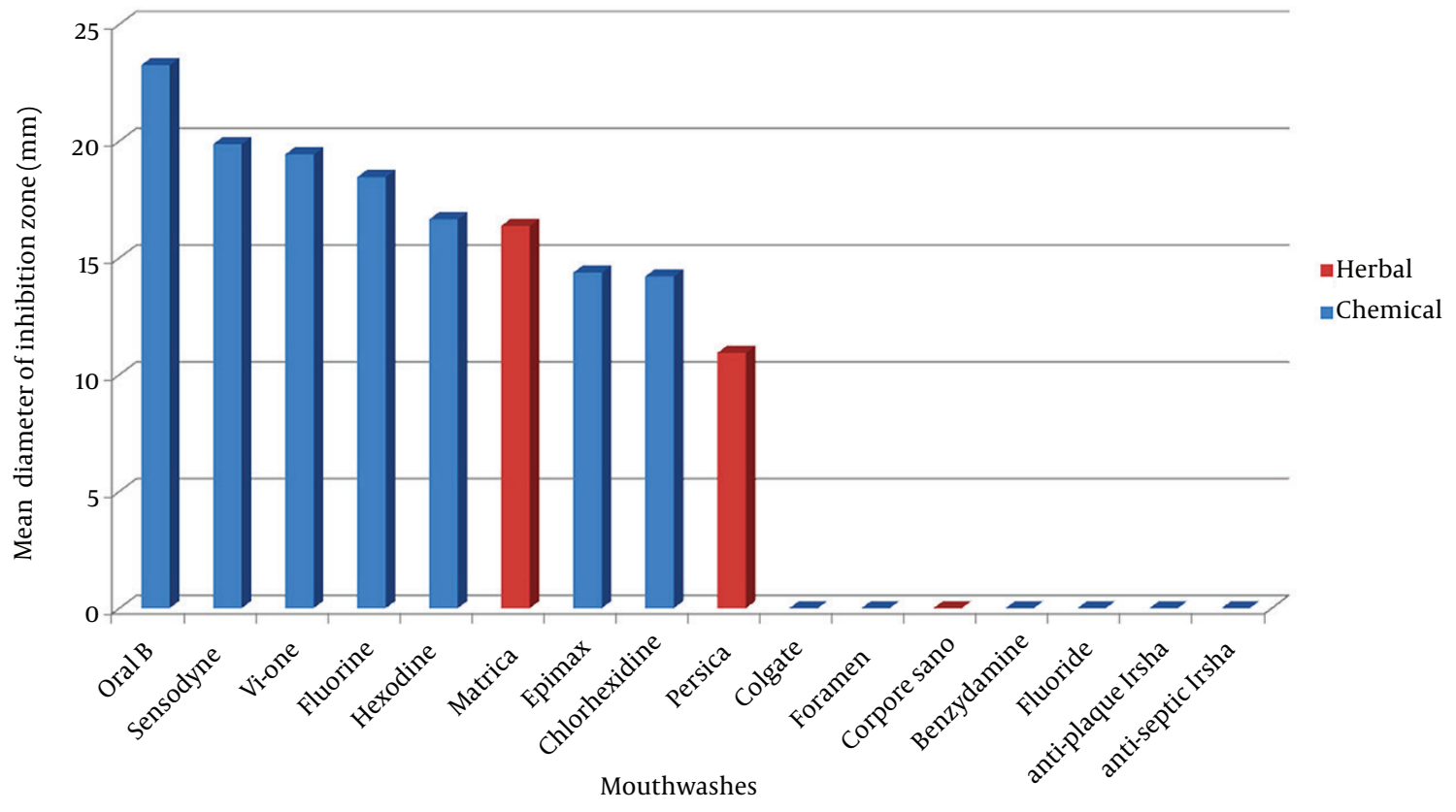

The unit of MIC is in $\mathrm{mg} / \mathrm{L}$. 


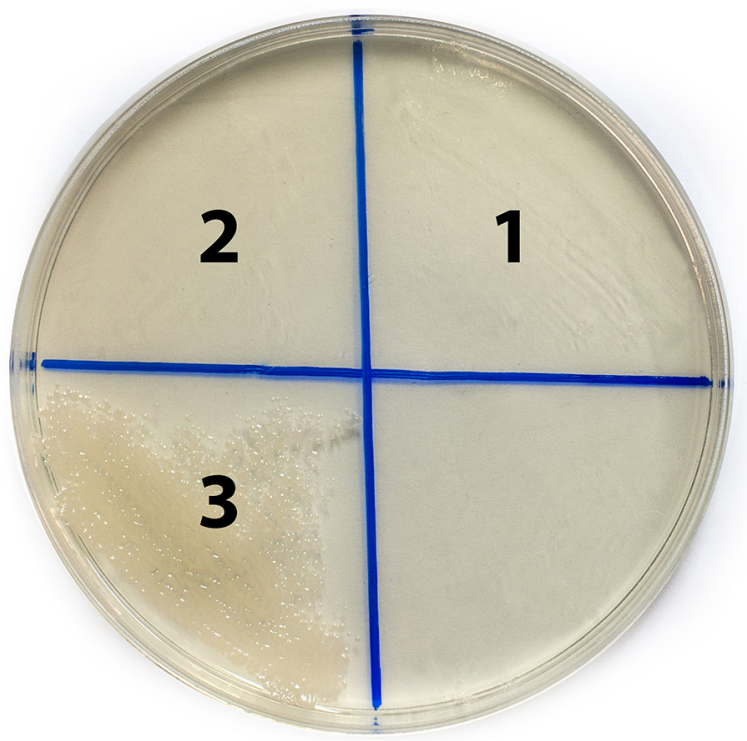

The numbers are based on the numbers of the MIC tubes. The second zone indicates the minimum fungicidal concentrations of Colgate mouthwash against C. albicans.

Figure 4. Minimum Fungicidal Concentration of Vi-one Mouthwash

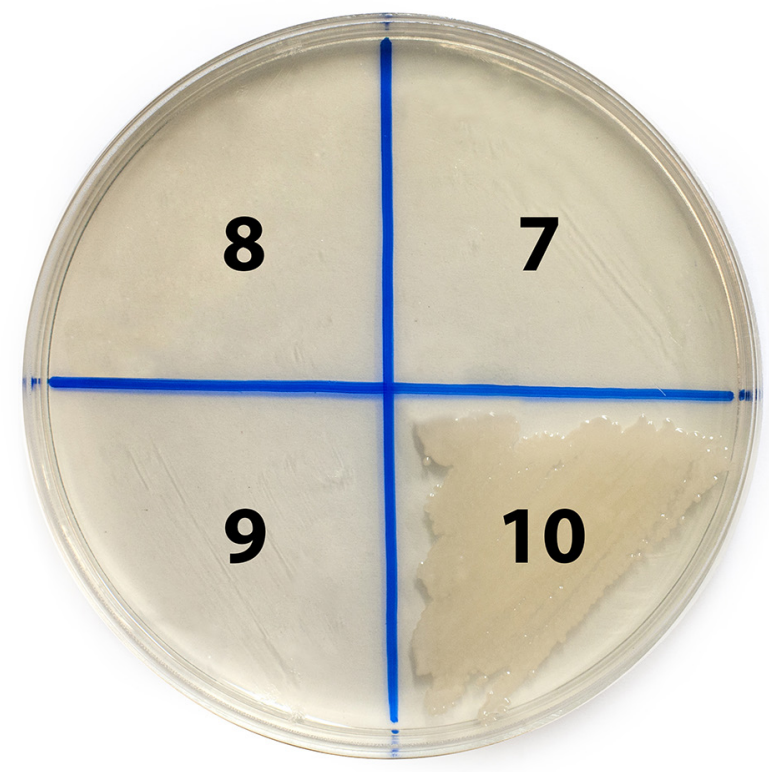

The numbers are based on the numbers of the MIC tubes. The ninth zone indicated the minimum fungicidal concentrations of Vi-one mouthwash against C. albicans.

\section{Discussion}

The use of antiseptic mouthwashes as a component of a complete oral hygiene regimen. Mouthwashes are a con- venient and accepted method of oral hygiene (28). In the current study, C. albicans indicated the most and the least sensitivity to Oral B and S. persica, respectively. Among different mouthwashes, C. albicans was resistant against fluoride, benzydamine, Colgate, Foramen, anti-septic Irsha and anti-plaque Irsha.

Giuliana et al. (29) investigated the in vitro antifungal effect of mouthwashes containing antimicrobial factor against Candida species and indicated that, chlorohexidine has antifungal properties and is effective against $C$. albicans. Also, in the current study, chlorohexidine was indicated to be effective against $C$. albicans, but in comparison with other mouthwashes, it showed a lower effect. Bajaj and Tandon (30) evaluated the effect of chlorohexidine on dental plaque, gum inflammation and microbial growth and indicated that microbial growth was decreased after the application of this substance. The current study investigated the effect of chlorohexidine against $C$. albicans and indicated that it has a lower effect in comparison with other mouthwashes, especially Oral B.

Meiller et al. (31) investigated the antifungal effect of $0.2 \%$ chlorohexidine against C. albicans. There is less information about chlorohexidine and its effect on $C$. albicans in comparison with the other mouthwashes. Chlorhexidine (CHX) is the most active agent, due to its wide spectrum of antimicrobial activity against a wide variety of organisms, including C. albicans (17). The mode of action of this substance is not entirely understood, but it is known that it acts as a fungicide and has a fungistatic function, leading to the coagulation of nucleoproteins and changes in cell walls allowing the possible escape of cytoplasmic components through the plasmalemma (17, 32). However, for oral use as a mouthwash, chlorhexidine has been reported to have a number of side effects, such as unpleasant taste, staining of teeth and tongue, gingival desquamation, taste disturbance and painful mucosa (18, 33). Chlorhexidine is not the first choice of drug for the treatment of Candida infections. However, the increase in the number of opportunistic infections caused by fungi, mainly in HIV infected individuals, and the great number of strains that have become resistant to the common antifungals has encouraged new research in relation to alternative treatments of such infections, among which is the use of chlorhexidine (32).

Among herbal mouthwashes examined by the agar diffusion method, Matrica and S. persica had the most and the least effect on C. albicans, respectively and Corpore Sano didn't have any effect on C. albicans. Almas (34) investigated the antibacterial effect of $S$. persica extract (50\%) in Persica mouthwash and chlorohexidine against oral microbes and C. albicans and concluded that, chlorohexidine mouthwash has more antimicrobial effect in comparison with extract of toothbrush plant and Persica has less antibacterial activity in comparison with chlorohexidine. It is important to note that Persica couldn't change the oral microbial and C. albicans level. In the current study, the results were similar to previous studies 
and Persica indicated less activity than chlorohexidine and Matrica against $C$. albicans with an average inhibition zone diameter of $10.93 \mathrm{~mm}$ and there was a significant difference between Persica and chlorohexidine anticandidial activity as indicated by the Tukey-HSD test $(\mathrm{P}<0.001)$. Alali and Al-Lafi (35) reported that there is considerable amounts of antibacterial agent in Persica leaves, which has activity against all types of oral bacteria and is comparable with different types of antiseptics. In the current study, Persica indicated mild anticandidial activity. Several studies have been conducted on Persica compounds and there isn't enough information about other mouthwashes. Based on our findings, there was no significant difference between herbal and chemical mouthwashes using independent T-test $(P=0.764)$. Using the agar diffusion method and according to the one-way ANOVA test, there was a significant difference within the group of chemical and herbal mouthwashes $(P<0.001)$. In the group of chemical mouthwashes, Oral B indicated a significant difference with other mouthwashes and in the group of herbal mouthwashes Matrica indicated a significant difference with other mouthwashes as indicated by the Tukey-HSD test $(\mathrm{P}<0.001)$.

Investigation of minimum inhibitory concentration and minimum fungicidal concentration in the group of chemical mouthwashes, revealed that Colgate and antiplaque Irsha had the least and Vi-one had the most activity with an average concentration of $0.250 \mathrm{mg} / \mathrm{L}$ and $0.001 \mathrm{mg} / \mathrm{L}$, respectively. In the group of herbal mouthwashes, also S. persica had the least activity $(0.093 \mathrm{mg} / \mathrm{L})$ and Matrica and Corpore Sano had the most activity $(0.006 \mathrm{mg} / \mathrm{L})$. The MIC and MFC results were the same and all mouthwashes had a minimum fungicidal concentration at the same level as the minimum inhibitory concentration. There was no significant difference between chemical and herbal mouthwashes using independent T-test ( $\mathrm{P}=0.879)$. al-Bagieh et al. (36) evaluated the antifungal activity of Persica extract and concluded that Persica concentrations more than $15 \%$ has a fungistatic effect on C. albicans.

In the current study, Persica a concentration of 0.093 $\mathrm{mg} / \mathrm{L}$ indicated fungistatic activity against C. albicans. Guggenheim and Meier (37) indicated that, chlorohexidine could significantly decrease the number of microorganisms in biofilm. In the current study chlorohexidine effectively decreased candidial growth (MIC 0.015 $\mathrm{mg} / \mathrm{L}$ ). Using the MIC and MFC methods and according to the one-way ANOVA test, there was a significant difference within the group of chemical mouthwashes ( $P$ $<0.001$ ) and there was no significant difference within the group of herbal mouthwashes $(\mathrm{P}=0.465)$.

In conclusion, as our study showed, among chemical and herbal mouthwashes, Oral B is a better chemical mouthwash. These mouthwashes can be used for infection treatment, rather than antibiotics, to decrease antibiotic resistance. Furthermore, clinical studies are needed to confirm the efficiency of in vivo application.

\section{Acknowledgements}

The authors would like to thank the Islamic Azad University of Karaj for their important technical support.

\section{Authors' Contributions}

All of the authors contributed to the development of the protocol, data abstraction, and preparation of the manuscript.

\section{Funding/Support}

This work was partly supported by the Islamic Azad University, Karaj Branch-Iran.

\section{References}

1. Dar-Odeh N, Shehabi A, Al-Bitar Z, A1-Omari I, Badran S, A1-Omiri M. Oral Candida colonization in patients with fixed orthodontic appliances the importance of some nutritional and salivary factors. . Afr J Microbiol Res. 2011;5(15):2150-4.

2. Akpan A, Morgan R. Oral candidiasis. Postgrad Med J. 2002;78(922):455-9.

3. Tapper-Jones LM, Aldred MJ, Walker DM, Hayes TM. Candidal infections and populations of Candida albicans in mouths of diabetics. J Clin Pathol.1981;34(7):70 6-11.

4. Salerno C, Pascale M, Contaldo M, Esposito V, Busciolano M, Milillo L, et al. Candida-associated denture stomatitis. Med Oral Patol Oral Cir Bucal. 2011;16(2):e139-43.

5. Premanathan M, Shakurfow F, Ismail AA BM, Ebrahim AT, MM A. Treatment of oral candidiasis (thrush) by Saccharomyces cerevisiae. Int J Med Med Sci. 2011;3(3):83-6

6. Jeddy N, Ranganathan K, Devi U, Joshua E. A study of antifungal drug sensitivity of Candida isolated from human immunodeficiency virus infected patients in Chennai, South India.J Oral Maxillofac Pathol. 2011;15(2):182-6.

7. Gonzalez Gravina H, Gonzalez de Moran E, Zambrano O, Lozano Chourio M, Rodriguez de Valero S, Robertis S, et al. Oral Candidiasis in children and adolescents with cancer. Identification of Candida spp. Med Oral Patol Oral Cir Bucal. 2007;12(6):E419-23.

8. Taguchi Y, Hayama K, Okada M, Sagawa T, Arai R, Abe S. Therapeutic effects of cinnamaldehyde and potentiation of its efficacy in combination with methylcellulose on murine oral candidiasis. Med Mycol J. 2011;52(2):145-52.

9. Lanzos I, Herrera D, Santos S, O'Connor A, Pena C, Lanzos E, et al. Microbiological effects of an antiseptic mouthrinse in irradiated cancer patients. Med Oral Patol Oral Cir Bucal. 2011;16(7):e1036-42.

10. Ramage G, Milligan S, Lappin DF, Sherry L, Sweeney P, Williams $\mathrm{C}$, et al. Antifungal, cytotoxic, and immunomodulatory properties of tea tree oil and its derivative components: potential role in management of oral candidosis in cancer patients. Front Microbiol. 2012;3:220.

11. Amini P, Araujo MW, Wu MM, Charles CA, Sharma NC. Comparative antiplaque and antigingivitis efficacy of three antiseptic mouthrinses: a two week randomized clinical trial. Braz Oral Res. 2009;23(3):319-25.

12. Satpathy A, Ravindra S, Porwal A, Das AC, Kumar M, Mukhopadhyay I. Effect of alcohol consumption status and alcohol concentration on oral pain induced by alcohol-containing mouthwash. J Oral Sci. 2013;55(2):99-105.

13. Gurgan S, Onen A, Koprulu H. In vitro effects of alcohol-containing and alcohol-free mouthrinses on microhardness of some restorative materials. J Oral Rehabil.1997;24(3):244-6.

14. Bagan JV, Vera-Sempere F, Marzal C, Pellin-Carcelen A, Marti-Bonmati E, Bagan L. Cytological changes in the oral mucosa after use of a mouth rinse with alcohol. A prospective double blind control study. Med Oral Patol Oral Cir Bucal. 2012;17(6):e956-61.

15. Chatterjee A, Saluja M, Singh N, Kandwal A. To evaluate the antigingivitis and antipalque effect of an Azadirachta indica (neem) 
mouthrinse on plaque induced gingivitis: A double-blind, randomized, controlled trial. J Indian Soc Periodontol. 2011;15(4):398401.

16. Uludamar A, Ozkan YK, Kadir T, Ceyhan I. In vivo efficacy of alkaline peroxide tablets and mouthwashes on Candida albicans in patients with denture stomatitis. J Appl Oral Sci. 2010;18(3):291-6.

17. Lanzos I, Herrera D, Santos S, O'Connor A, Pena C, Lanzos E, et al. Mucositis in irradiated cancer patients: effects of an antiseptic mouthrinse. Med Oral Patol Oral Cir Bucal. 2010;15(5):e732-8.

18. Al-Bayaty FH,, AI-Koubaisi AH,, NAW A, MAA. Effect of mouth wash extracted from Salvadora persica (miswak) on dental plaque formation: A clinical trail. J Med Plant Res. 2010;4(14):1446-54.

19. Goyal M, Sasmal D, Nagori BP. Salvadora persica (Meswak): Chewing Stick for Complete Oral Care. Inter J Pharmacol. 2011;7(4):440-5.

20. Al-Sadhan RI, K A. Miswak (chewing stick): a cultural and scientific heritage. Saudi Dental J.1999;11(2):80-7.

21. Sher H, Al-yemeni MN, L W. Ethnobotanical and antibacterial potential of Salvadora persica l: A well known medicinal plant in Arab and Unani system of medicine. J Med Plant Res. 2011;5(7):1224-9.

22. McCourtie J, MacFarlane TW, Samaranayake LP. Effect of chlorhexidine gluconate on the adherence of Candida species to denture acrylic. J Med Microbiol. 1985;20(1):97-104.

23. Pizzo G, Giuliana G, Milici ME, D'Angelo M. Effect of antimicrobial mouthrinses on the in vitro adhesion of Candida albicans to human buccal epithelial cells. Clin Oral Investig. 2001;5(3):172-6.

24. Nayak PA, Nayak UA, Mythili R. Effect of Manuka honey, chlorhexidine gluconate and xylitol on the clinical levels of dental plaque. Contemp Clin Dent. 2010;1(4):214-7.

25. Takagi Y, Hattori H, Adachi H, Takakura S, Horii T, Chindamporn A, et al. Genotypes of Candida albicans involved in development of candidiasis and their distribution in oral cavity of non-candidiasis individuals. Med Mycol J. 2011;52(4):315-24.

26. Canton E, Peman J, Carrillo-Munoz A, Orero A, Ubeda P, Viudes A, et al. Fluconazole susceptibilities of bloodstream Candida sp. isolates as determined by National Committee for Clinical Labo- ratory Standards method M27-A and two other methods. J Clin Microbiol. 1999;37(7):2197-200.

27. Martos AI, Romero A, Gonzalez MT, Gonzalez A, Serrano C, Castro $\mathrm{C}$, et al. Evaluation of the Etest method for susceptibility testing of Aspergillus spp. and Fusarium spp. to three echinocandins. Med Mycol. 2010;48(6):858-61.

28. Gaffar A, Afflitto J. General principles for the delivery of active agents from mouthrinses. Int Dent J. 1992;42(4 Suppl 1):253-62.

29. Giuliana G, Pizzo G, Milici ME, Musotto GC, Giangreco R. In vitro antifungal properties of mouthrinses containing antimicrobial agents.J Periodontol. 1997;68(8):729-33.

30. Bajaj N, Tandon S. The effect of Triphala and Chlorhexidine mouthwash on dental plaque, gingival inflammation, and microbial growth. Int J Ayurveda Res. 2011;2(1):29-36.

31. Meiller TF, Kelley JI, Jabra-Rizk MA, Depaola LG, Baqui AA, Falkler WA, Jr. In vitro studies of the efficacy of antimicrobials against fungi. Oral Surg Oral Med Oral Pathol Oral Radiol Endod. 2001;91(6):663-70.

32. Machado FC, Portela MB, da CUNHA AC, de Souza IPR, de Araújo Soares RM, de Araújo Castro GFB. Antifungal activity of chlorhexidine on Candida spp. biofilm. Rev Odontol UNESP. 2010;39(5):271-5.

33. Van Zyl AW, WFP VH. Mouthwash: A review for South African health care workers. SA Fam Pract. 2010;52(2):121-7.

34. Almas K. The antimicrobial effects of extracts of Azadirachta indica (Neem) and Salvadora persica (Arak) chewing sticks. Indian JDent Res. 1999;10(1):23-6.

35. Alali F, Al-Lafi T. GC-MS analysis and bioactivity testing of the volatile oil from the leaves of the toothbrush tree Salvadora persica L. Nat Prod Res. 2003;17(3):189-94.

36. al-Bagieh NH, Idowu A, Salako NO. Effect of aqueous extract of miswak on the in vitro growth of Candida albicans. Microbios. 1994;80(323):107-13.

37. Guggenheim B, Meier A. In vitro effect of chlorhexidine mouth rinses on polyspecies biofilms. Schweiz Monatsschr Zahnmed. 2011;121(5):432-41. 